NBER WORKING PAPER SERIES

THE RELATIONSHIP BETWEEN JOB CHARACTERISTICS AND RETTREMENT

Michael Hurd

Kathleen McGany

Working Paper No. 4558

NATIONAL BUREAU OF ECONOMIC RESEARCH 1050 Massachusetts Avenue

Cambridge, MA 02138

December, 1993

Financial support From the University of Michigan and the National Institute on Aging is gratefully acknowledged. Many thanks to Nancy Cole for research assistance. This paper is part of NBER's research program in Aging. Any opinions expressed are those of the authors and not those of the National Bureud of Economic Research. 
NBER Working Paper \#4558

December 1993

\title{
THE RELATIONSHIP BETWEEN JOB CHARACTERISTICS AND RETIREMENT
}

\begin{abstract}
We study the influence of job characteristics on prospective retirement as measured by the probability of working past age 62 or 65 . The characteristics fall into three broad classes: physical and mental requirements, job flexibility including employer accommodation to older workers, and financial aspects such as pensions and health care insurance. Using data from the Health and Retirement Survey, we find that physical and mental job requirements have a rather small influence on prospective retirement, whereas measures of job flexibility and financial aspects of the job are important determinants.
\end{abstract}

Michael Hurd

Department of Economics

SUNY, Stony Brook

Stony Brook, NY 11794

and NBER
Kathleen McGarry

Department of Economics

UCLA

Los Angeles, CA 90024-1477

and NBER 
1. Inlroduction

Empirical studies of retirement behavior have generally focused on the influence of financial varjables such as pensions, Social Security, wealth and wages. In a broader framework, however, the decision to retire will involve weighing the utility of leisure against the utility from working, including the utility from an increase in wealth. From this point of view workers will retire from unpleasant, difficult jobs at a different rate than from pleasant, easy jobs. Besides eliminating the estimation problems that will follow if working conditions are correlated with financial variables, a complete investigation of job characteristics on retirement behavior should improve our understanding of the retirement process.

An even broader perspective would want to account for the entire choice set facing the worker. There are many aspects of the choice set. Here we focus on two. The first has to do with the ability of a worker to vary the volume of work without changing jobs. There is considerable empirical evidence that workers have little flexibility with respect to hours per day, days per week or weeks per year (Hurd, 1993). If a worker is constrained to work more or fewer hours than is desired, he may choose to retire at a different age than in the absence of a constraint. For example, a worker who wants gradually to reduce hours per week as he ages but is constrained, may retire earlier than he would were the constraint removed.

A second aspect of the choice set is the availability of alternative other jobs with different hours and wage combinations. Past studies typically find that an older worker who leaves a career job will suffer a wage cut of 35\%-50\% (Gustman and Steismeier, 1985, Jams, 1987)." But these sudies are based on observations in panel data: we only know the outcomes of those who remain in the labor force, not those who leave completely. Those who leave completely perhaps face even less desirable alternatives.

The Health and Retirement Survey (HRS) has a number of questions about job characteristics of a rather conventional nature. In addition, however, there are questions about the ability and desire of a worker to vary hours, and a few questions about the prospects of other employment. In cross-section, these questions would te of liule use in understanding retirement because they are only asked of workers; however, in the HRS there are several questions about the prospects of retirement. In particular, workers are asked about retirement plans, including the expected age of retirement. This measure of the expected age at retirement is quite

\footnotetext{
${ }^{1}$ See Hurd, 1993, for a discussion of this literature.
} 
conventional, and has been of limited use in other data sets because the answer is hard to intepret. Is the response the most likely retirement age, the mathematical expectation, the mode, or what? However, in addition to this question, the HRS has innovative questions about the probability of working past the age of 62 and of 65 . These questions show considerable promise, not just for understanding retirement but other aspects of individual decision making.

This paper has several goals. The first is to analyze the data about job characteristics in the first wave of the HRS, and to find their variation and correlates. The second is to analyze the data on other aspects of the job, in particular hours constraints. The last goal is to find the influence of job characteristics and other variables on the measures of anticipated retirement. Because of the innovative nature of the probability questions, most of our work will use them; we will, however, compare the conventional expected retirement age with the probabilities so that we may understand both better.

\section{Previous findings about job characteristics}

It is often but not universally found that more physically demanding occupations are associated with early retirement. In the New Beneficiary Survey, workers in physically demanding jobs are less likely to work after the initial receipt of Social Security benefits than other workers (Holden, 1988). In the Retirement History Survey (RHS) Gustman and Steinmeier (1986) found a smaller proportion of workers in more physically demanding occupations as age increases, suggesting that such workers leave the labor force at younger ages.

Filer and Petri (1988) argued that job characteristics determine an appropriate retirement age for a specific job and that the retirement age in turn determines the structure of the pension program. They found that many job characteristics are significant predictors of early retirement, including heavy physical demands and stress. Flexibility of employment, as measured by the possibility of self-employment or part-time employment, increased the retirement age.

Hayward, Grady, Hardy and Sommers (1989) used factor analysis to derive four job characteristic groupings; substantive complexiry, manipulative skill, physical demands and social skill. In a hazard model they found that substantive complexiry and physical demands are both significant predictors of retirement; complexity lowers the retirement probability and physical demands increases it. Other variables such as compulsory retirement, age, health and pension eligibility operate in the expected direction.

Not all studies have found a relationship between job characteristics and retirement. For 
example, Bartel (1982) used the National Longitudinal Survey of Older Men to compare the relative importance of specific job characteristics in predicting quit probabilities. She found that repetitive work has litule effect on the quit rate of older men. Furthermore, other job characteristics such as whether the job requires strength, involves bad working conditions, or is stressful are not significant predictors of the quit probability of older men.

Quin (1977) examined labor force status as a function of personal and financial characteristics, labor market characteristics, and job characteristics. Financial characteristics such as wealth, Social Security and pension eligibility are important predictors of labor force participation for 58-63 year old men in the RHS, but low autonomy on the job, stress and bad working conditions are not significant predictors of participation.

Alhough these studies have mixed results on the magnitude of the influence of job characteristics on retirement, they have at least established that they should be considered further.

\section{Hours of work restrictions.}

If there were no constraints on the choice of hours of work, we would expect that as workers age and tastes shift toward leisure, they would desire to withdraw gradually from the labor force. Although there is some shift to part-time work following a separation from a fulltime career job, a substantial majority leave full-time work for full-time lejsure (Rust, 1990; Berkovic and Stern, 1991; Quinn, Burkhauser, and Myers (1990). Among those who reduce hours, all but a small fraction change jobs, often to another occupation and industry (Ruhm 1990), and earn much less per hour. It is unlikely that workers would make such a change, wilh the accompanying income reduction, if their career employer allowed them to reduce hours on their current job.

The conclusion is that hours constraints are an important aspect of the employment environment, and that it is likely they help determine the age of retirement.

\section{Data}

The HRS is a nationally representative sample of individuais born in the years 1931 $1941 .^{2}$ Almost all the interviews were done in 1992, so we will refer to 51-61 year-olds as the

\footnotetext{
${ }^{2}$ See Juster and Suzman (1993) for a description of the HRS.
} 
age-eligible population even though not all were in that age range at the time they were interviewed. The spouse of an age-eligible individual was interviewed, and data from that interview is included in the HRS data set even if the spouse was not age-eligible. The HRS is projected to be a panel survey of two-year periodicity that will last for at least 10 years.

We use data only on full-time workers ( 35 hours or more per week) because our main measure of anticipated retirement in the HRS refers to full-time work after the age of 62 . In that there is very little movement from part-time work to full-time work in the age range of the HRS, we do not want our analyses to be influenced by the tastes and perceptions of part-time workers. For population comparisons, our sample is restricted to the age range 51-61, and we use sampling weights to account for oversampling of blacks, Hispanics and Floridians. We do not use weights in regressions because we have no reason to believe the regression function varies with the sampling frequency. ${ }^{3}$

For analysis we use a sample of men aged 51-61 and women aged 46-61: below the age ranges the sample sizes are small; people above the age range will not be useful in studying retirement at age 62 because they are already that age or older. We realize that outside of the age range 51-61, the sample is not representative of the population because a respondent must be a spouse of an age-eligible person. However, about $23 \%$ of the sample is outside the age range 51.61 , which is a large fraction to drop in the absence of a compelling reason.4

We include only wage and salary workers because we want to study the effects of restrictions on hours of work; yet the question about hours restrictions was not asked of the selfemployed. These selection criteria along with several other rather minor selection rules produced a sample of 3383 full-time wage and salary workers. ${ }^{5}$

\section{Measures of retirement}

\footnotetext{
${ }^{3}$ If we thought that the coefficieats in a regression function varied in the population, and that the coefficients were systematically differeat in the subpopulation that is oversanpled, we would use sampling weights to yield regression coefficients thy are the avernge of the coefficients in the population. We bave no reason to think that the coefficients vary in alch a way. Furthermore, if we did, it would be better to estimate over the subsumples sepantely mther than weighting.

'For analysis we often would like to know if a model seeme to hold for any population provided the population was not chosen either to favor or disfavor the model. Based on this reasoning we imagine that most analysts will want to use the part of the HRS outside of the age range 51-61.

"We delete those in the military, and proxy responses, as well as workers who do not receive compensalion in the form of a wage or salary-
} 
In the initial wave of the HRS we only observe job characteristics and job-related financial variables of those who are still working, so we cannot study actual retirement. However, the HRS has several variables that measure retirement prospectively. We will use several of these. Our main variables are responses to the questions: (On a scale of zero to 10 where 0 means absolutely no chance and 10 equals absolute certainty),

"Thinking about work generally and not just your present job, what do you think are the chances that you will be working full-time after you reach age 62 (65)?"

We rescaled the responses to the interval $[0,1]$ and we will treat them as probabilities. Generally we think of them as conditional probabilities, the probabilities of working full-time at 62 or 65 given full-time work al age $t$. It should be apparent, however, that the question is ambiguous. It could refer to anyrime after the $62 \mathrm{nd}$ birthday or it could refer to sometime after the respondent is no longer 62. As we will see, some respondents seem to have had the first interpretation and some the second.

We call the probabilities P62 and P65. We will refer to them as if they were probabilities of working, and to 1-P62 and 1-P65 as probabilities of retiring. They are not exactly that, of course, because they refer to full-time work, not employment.

We want to use these probabilities as variables to be explained by job characteristics and financial variables just as if they were actual retirement probabilities. Before we do that, however, we will give some descriptive statistics that we hope will increase confidence that they are predictive of actual retirement.

As a way of validating their use, we compare P62 and P65 with population averages. We estimated the fraction of the population 55-59 working full-time and the fraction aged 63 working full-time from estimates of the fraction of full-time workers among all workers by age, and from labor force participation rales by age. According to this calculation the probability of working full-time at age 63 conditional on working full-time at ages $55-59$ is 0.457 . The average of P62 over the $55-59$ year-old fult-time workers in the HRS is 0.478 .

We can make an additional comparison based on the HRS daa by using the observations of 62 and 63 year-old males who were interviewed but are not in the age-eligible population. the HRS.

${ }^{6}$ See Hurd and McGarry (1993a) for a more detailed analysis of these and other probabilily variables in 
They are hushands of age-eligible wives, and while they are not exactly representative of the 62 and 63 year-old male population (having to be married to younger women to be in the survey) we inagine they are sufficiently representative to give good estimates of the conditional probability of working full-time. We estimated the probability of working full-time at age 62 conditional on working full-lime at $I$ from the fraclion of the HRS married males aged 62 who are working fulitime and the fraction of the HRS married males working full-time at age $t$. We estimated in a similar way the probability of working to age 63 conditional on working at age $t$.

According to our estimates the average conditional probability of working to 62 is 0.72 (averaged over 55-61 year-olds), and the average conditional probability of working to 63 is 0.44. The average of P62 over 55-61 married males is 0.50. Furthermore, at each age from 55 to 61 the average of $P 62$ is bounded by our estimates of the conditional probabilities of working to 62 and to 63 .

We conclude that the average of $\mathrm{P} 62$ is reasonably close to population averages and to conditional probabilities calculated from the frequencies of full-time work in our sample. 'This should increase our confidence that they are good measures of prospective retirement.

Other measures of anticipated retirement

The HRS asked workers if they had made plans or thought about retirenert, and if so at what age did they plan to retire completely, change jobs, reduce hours, or become self-employed. If P62 and P65 are informed probabilities, we expect that they would vary according to whether someone has thought about retirement.

Table 1 has the means of P62 and P65 by work plans. Most of these workers (all 61 or younger) have not thought about retirement or have no plans (43 percent). Among those who have thought about retirement, about 11 percent plan never to stop working. Among the remainder about 44 percent say they will leave the labor force completely. 'This is a much smaller percentage than was observed to retire completely from full-time career jobs in the Retirement History Survey (RHS). The comparable percentage in the RHS would be about 73 percent.' If this holds in the HRS panel, it will show a trend to more job switching and hours reduction following departure from a full-time career-type job than has been observed in the past.

There are large differences in P62 varying from 0.31 to 0.63 as the type of retirement

\footnotetext{
${ }^{7}$ Our calculation hased on data in Quinn, Hurkhauser and Myers, 1990.
} 
planning varies. It should be noted that the responses of those who ptan never to stop working are not necessarily inconsistent with their averages of P62 and P65. Most who continue to work after the normal retirement age switch to part-time work; someone with a definite plan to reduce hours at age 60, and then work for many more years might answer "never stop" and correclly report zero for P62, since P62 asks aboul full-time work.

The variation in P65 is even greater than in P62: among those who plan to stop working altogether the average probability of working full-time at age 65 is only 0.087 .

If a respondent reports that he plans to reduce hours, retire completely, change jobs, or work for himself, he is asked a follow-up question about the age at which he plans to change his labor force status. We use these answers to define an expected retirement age (ERET). It is the age at which someone expects to reduce hours or retire completely. We define ERET in this way to make comparisons with P62 and P65 which refer to full-time work. ERET is an alternalive measure of retirement anticjpations.

We have 1401 observations on ERET frors which we calculated a kind of retirement hazard rate. It is the number who expect to retire at age $t$ divided by the number who expect to be working at age $t-1$. We say that someone who gives ERET $=t$ expects to relire at $t$, so that the number who expect to work at age $t-1$ is the number working at all ages less than $t$, minus the number with ERET less than $t$. This would be the same as an actual retirement hazard rate if workers actually do retire at the age given by ERET.

Figure 1 shows retirement hazard rates calculated in this way over 51 year-olds and over 54 year-olds. The hazard rate of the 51 year-olds has a rather large spike at age 55 . A similar but smaller spike is found in actual hazards in the population. However, we imagine that these workers have begun to think about retirement at this early age at least partly because they are in jobs that have incentives to retire at 55 . Therefore, more in this group will actually retire at 55 than in the population. The hazards of both 51 and 54 year-olds have spikes at 62 and 65 . but they are much larger than what is found in panel data such as the RHS."

Almost none of the workers in their early 50's who have plans for retirement expects to work past 65 and few past 62 . Thus the retirement hazard rates are very large at those ages.

\footnotetext{
'The hazard rale of workers older than 54 look very similar to the hazard rates of the 54 year-oids, so we do not present them.

There is oo obvious explanation for why the hazard of 54 year-olds has no spike at 55 : the hazard rates of 52 and 53 year-olds have spikes at 55 similar to those of the 51 year-olds.
} 
We speculate that this is party caused by their having thought about retirement, meaning they plan to retire earlier than in the population. It may also be an uninformed response: in their early 50 s most workers probably give usual or standard retirement ages. Thus, few would have ERET greater than 65, and, indeed, in our sample of 1401 , just 26 or 1.8 percent have ERET greater than 65. A different kind of explanation is that ERET is the most probable retirement age. Few would have a most probable age later than 65 even though substantial numbers could end up retiring after 65 . This shows a weakness of a measure like ERET.

We expect that P62 and P65 will vary systematically with ERET. For example, someone with ERET less than 62 should have a smali value of P62 whereas someone with ERET greater than 62 should have a large value. Figure 2 shows averages of P62 and P65 by ERET, and they support our expectation. For example, the average P62 among workers with ERET $=56$ is just 0.1 . The average remains small until at age 61 when it increases from 0.14 to 0.23 and then to 0.67 at age 63. We interpret the increase in two steps (61-62 and 62-63) to be further evidence that the question about the probability of working after reaching age 62 is ambiguous. If the question meant "after the $62 \mathrm{~nJ}$ birthday," everyone with ERET $=62$ should have $\mathrm{P} 62=1.0$. The rather small value ( 0.23 ) leads us to believe that most respondents interpreted the question to mean "working while $62^{\text {" }}$ or "most of the time while $62^{\text {" }}$ or possible "at the 63 rd birthday." The fact that P62 does not reach 1.0 at ages greater than 63 shows that ERET should not be taken to the age of retirement with probability one.

P65 has a similar pattern with age, and except for age 55 it is always less than P62."10

We conclude from this comparison that P62, P65 and ERET show internal consistency and that it is reasonable to consider P62 and P65 to be conditional probabilities of full-time work. Whether the age is 62 or 63 for P62, or 65 or 66 for P65 is ambiguous.

5. Job Characteristics data in the HRS.

Past research has generally concentrated on physical and mental demands of the joo. Therefore, we first study the effects of these kinds of characteristics on prospective retirement. In section 5.2 we will consider a larger class of job characteristics such as hours constraints.

5.1. Physical and mental job requirements.

\footnotetext{
${ }^{10}$ The large value of $P 65$ at age 55 is based on just five observations.
} 
The HRS asked a number of questions of workers about the characteristics of their jobs. The questions were meant to measure the physical and mental demands of the job, the pleasantness of the working environment, and so forth. The questions were in two formats. The first format is

F82. ..."Thinking of your job, please tell how often these statements are true." Choices are (1) all or almost all of the time, (2) most of the time, (3) some of the time. (4) none or almost none of the time.

The particular questions we will use are

F82a "(My job requires) lots of physical effort. (PHYSICAL)

b. ... lifting heavy loads. (LIFTING)

c. ... stooping, kneeling, or crouching. (BENDING)

d. ... good eyesight. (EYES)

e. ... intense concentration or attention. (ATTENTION)

f. ... skill in dealing with other people. (PEOPLE)

g. ... me to work with computers. (COMPUTERS)

h. ... me to analyze data or information. (DATA)

j. ... me to keep up with the pace of others. (PACE)

k. ... me to do the same things over and over. (REPETITION)

m. ... that I learn new things. (LEARN)

n. I have a lot of freedom to decide how I do my own work. (FREEDOM)

p. The people I work with are helpful and friendly. " (COWORKERS)

The second format is

F83. "Here are some more statements Liat are true for some people's jobs but not for others. Again thinking of your job, this time please indicate how much you agree or disagree with each statement." Possible answers are (1) strongly agree, (2) agree, (3) disagree, (4) strongly disagree.

The questions we will use from F83 are 
"b. My job requires me to do more difficult things than it used to. (DIFFICULT)

c. My job requires a very good memory. (MEMORY)

d. My job involves a lot of stress." (STRESS)

In the first format the questions ask for objective descriptions of the job, not the attitude of the worker toward the job characteristics. (For example, the worker is not asked if he likes lifting heavy loads). We would expect, however, that over time workers would sort themselves according to job characteristics. Thus the objective duty of lifting a 15 pound load might not be called heavy lifting by someone who does lift 15 pounds, whereas it would be by someone else. Of course, if the objective is to explain retirement behavior, it is important to understand how the worker views the job. The self-reported nature of these variables should be kept in mind when comparing the estimates presented here to those of previous studies.

The questions in the second format seem to be less objective because it would be difficult to find objective measurements of difficulty and stress. Furthermore, the second format asks for agreement or disagreement, not whether something happens some of the time or all of the time.

These seems to be no narural scaling of the answers; in particular, without further investigation we would not want to convert the answers to a scaler. The most important reason is that many of the behavioral responses to variation in the characteristics are probably not monotonic. For example, most people would probably prefer some repetition on a job, rather than doing repetitive work either all or none of the time. Similarly, a good job probably requires intense concentration some of the time; a boring job requires it none of the time and an overly difficult job requires it all of the time. Similar arguments can be made about most of the job characteristics.

The job characteristics define 64 categorical variables. We reduce these to 54 by combining some of the responses with very low frequencies. For example, we combine EYES3 and EYES4 (job requires good eyesight some of the time or none of the time) because the response rates were 7 percent and $\mathbf{3}$ percent respectively. Furthermore, we judge that some of the response categories are not meaningfully different for some of the job characteristics. ${ }^{11}$ We have, therefore, 54 categorical variables for 16 job characteristics, giving us 38 degrees of freedom after normalization.

\footnotetext{
"We combine categories 1 and 2 for LIFTING and categories 3 and 4 for EYES, ATTENTION, PEOPLE, REPEITTION, LEARNING, COWORKERS, MEMORY, STRESS and DIFFICULT.
} 
Our main focus in this section is the effect of job characteristics on retirement. Our analysis of the last section leads us to conclude that P62 and P65 are good proxies for actual retirement probabilities; in this section we wilt use them in place of actual retirement. For our first set of results we estimated the linear regression of $\mathrm{P} 62$ and $\mathrm{P} 65$ on the 38 dummy variables that define our measures of job characteristics to find if simple data description showed any parterns. ${ }^{12}$ The regression of P62 is significant at the 5\% level but not at the $1 \%$ level; the regression of $\mathrm{P} 65$ is significant at the 1 percent level.

Table 2 has selected coefficients. Our selection criterion for reporting coefficlents is to include all the coefficients from any job characteristic that had at least one categorical variable for either P62 or P65 significant at the 10 percent level.

The partern of the signs of the coefficients in the P62 equation is consistent with the pamern of the P65 coefficients, indicating that except for scaling, most respondents gave similar responses to the questions about P62 and P65. Although most of the findings are what we would expect, those about the physical demands of the job are not. The literature suggests that physical demands are important predictors of early retirement. Yet both PHYSICAL and BENDING had small, insignificant coefficients (not shown in the table). Only LIFTING has a significant coefficient, but relative to the literature, it has the wrong sign: LIFTING4 (job never requires heavy lifting) reduces P62 by 0.054 compared with a job where heavy lifting is required always or most of time.

P62 and P65 are not monotonic in two of the job characteristics, EYES and STRESS. Jobs that require moderate use of the eyes and jobs with moderate stress are associated with higher P62 and P65 than jobs at the extremes. Jobs that require intensive use of the eyes or that involve a lot of stress are unattractive because of the obvious physical and mental demands. Jobs that require litrle use of the eyes or have little stress may be jobs that are boring and uninteresting.

The other job characteristics have the pattern of signs that we would expect: constant repetition, no freedom and increased difficulty lead to smaller P62 and P65. Furthermore the effects are about the same: both for P62 and P65 the diffetence in the probability between the first category and the last category is 0.05 for REPETITION, 0.06 for FREEDOM and 0.06 for DIFFICULT.

\footnotetext{
${ }^{12}$ This regression is similar to Files and Petri (1988). Later in this paper we will give results from regressions that include a number of financial and personal explanatory variables.
} 
It is hard to judge whether these are important effects. From estimates of the conditional probabilities of working to ages 61,62 and 63 in the population, we estimate that an increase in P62 of 0.10 is roughly equivalent to an increase in worklife of one year for someone working at age 55 (Hurd and McGarry, 1993b). Therefore, we would judge that a change in P62 of 0.05 is a small to moderate change.

We conclude that although not many of the coefficients are significant even at the 10 percent level (11 out of 76) the ones that are significant for the most part have the expected signs; the exceptions being the job tharacteristics associated with physical demands. A linal conclusion is that, in general, the characteristics cannot be reduced to scalers: the probabilities are not monotonic in two of the six characteristics.

\subsection{Other job characteristics.}

In this section we discuss several other kinds of job characteristics. The first we roughly characterize as measures of attitudes toward older workers. Table 3 has the distribution of responses to two questions that may represent age discrimination. About 17-18 percent agree or strongly agree with the statements. ${ }^{13}$ It is difficult to judge whether this is a large percentage: perhaps the optimistic way to view the distributions is that $82-83$ percent disagree. In results which we do not report here, we found no evidence that these distributions change with age of the respondent.

The last question shows that most employers will not accommodate a desire for job flexibility: about two-thirds of the gample cannot move to less demanding work even with a wage reduction. Yet, in surveys most workers say they would like job flexibility. For example, many would like to reduce hours gradually as they age rather an retiring abruptly (Jondrow, Brechling and Marcus, 1987). We imagine this lack of flexibility will induce many to retire.

An additional measure of job flexibility is the ability to vary hours per day, days per week, or weeks per month. The HRS asked workers about flexibility as follows "Could you increase the number of hours in your regular work schedule?" Those who answered "no" were then asked "Would you like to do so if your earnings were increased in the same proportion?" Notice that the questions are somewhat deficient in that the first question made no reference to a proportionate increase in earnings. Workers were also asked "Could you reduce the hours in

\footnotetext{
${ }^{13}$ In later work we combine the first two categories because of the low frequency in the first.
} 
your regular work schedule?" If "no" they were asked "would you like to do so even if your earnings were reduced in the same proportion?" Obviously the aim of the followup questions was to keep the wage rate constant.

The importance of the question comes from considerable evidence in panel data that few workers reduce hours on their main, career jobs: most workers leave full-time jobs to retite completely. Those who do not leave the labor force change jobs to a different occupation and/or industry, and that the wage rate falts considerably at the change in jobs. ${ }^{14}$

Table 4 has the distributions of responses to the hours flexibility questions. Just 12.9 percent have complete flexibility either to increase or decrease hours. A greater percentage can increase ( 36 percent) than can decrease (24 percent) but this may be caused by the question's failure to refer to a change in compensation in response to a change in hours: if respondents interpreted the question to mean a change in hours with no change in earnings, many might well think their employers would not bar them from working more, but would prevent them from working. ${ }^{\text {s }}$

Apparently a substantial fraction of workers face hours constraints; yet the consuraint is not binding in the sense that they do not desire to break the constraint. For example, 32.7 percent say they are completely constrained ( $\mathrm{can}$ neither increase nor decrease hours); yet they neither want to increase nor want to decrease. An additional 26.4 percent $(18.1+8.3)$ are constrained on one side or the other, but the constraint is not binding. Taken at face value these high percentages show that people accommodate to their constraints, and after the accommodation they prefer the new constrained point. For example, if workers form car pools or make child care arrangements based on their known work schedule, it would be inconvenient to change hours. They may therefore prefer the complete package of constrained hours and their other arrangernents to a hypothetical change in hours. Fourteen percent cannot reduce hours and the constraint is binding, and 15 percent cannot increase but would like to.

Table 5 offers some explanations for these responses. Thoșe with hours flexibility in eicher direction work the most hours, have the highest wage rates, the most education and mostly

\footnotetext{
${ }^{14}$ See Gustman and Steinmeier (1984, 1985), Berkovic and Sterm (1991), Rust (1990), Quinn and Burkhauer (1990), Hurd (1993), Ruhm (1990) and Ians (1987).

${ }^{15}$ The percentage that can reduce bours can be compared with the responses in Table 5 where 34 pereent agreed that their employers would let them move to a less demanding job. These are, of course, two dimeasions to job flexibility. The difference in the response rate may well be due to the difference in the questions: onc made reference to a job change whereas the other did not.
} 
have white collar jobs. Apparently job flexibility is another dimension of a well-paying job. Those who want to increase hours but are constrained from doing so work fewer hours than those who do not want to, and they have less household wealth. ${ }^{16}$

Among workers who cannot decrease hours, those who want to decrease hours work more than those who do not want to: 1.8 hours more per week, which is a statistically significant difference. Their other characteristics are similar with the notable exception of household wealth: it is $\mathbf{\$ 8 4}$ thousand greater, the highest of any group. ${ }^{17}$ Apparenlly the constraint is binding both because hours were constrained to be higher, and because a wealth effect caused desired hours to be lower.

Job flexibility influences prospective retirement: P62 and P65 vary with hours constraints as we would expect (Table 6). There is liple difference between those who can increase and those who can decrease. The interesting differences are among those who are constrained. Those who want to increase hours have larger values of P62 and P65 and the diflerence is statistically significant. Apparently they respond to the hours constraint by working more years. Those who want to reduce hours but are constrained, have lower probabilities of working than those who do not want to reduce hours. Again the differences are signifificant. Especially at age 65, the difference will lead to a considerably lower participation rate, about one-third lower.

\section{Determinants of probabilities of working.}

In that job characteristics are correlated with other aspects of a job such as pay and pension availability, we estimated the regression of P62 and P65 on job characteristics and a much larger set of variables. We made the regression of P62 a linear function of age, the 38 categorical variables relating to the 16 physical and mental job characteristics that we discussed in section 5.1, a number of other job characteristics and individual characteristics. Because P62 is a conditional probability, the regression is related to a particular specification of a retirement hazard function. In particular, we estimate P62 $=\mathrm{P}$ (working full-time sfter 62 | working fulltime af age $i$; $T$ wich is, in general, a function of a number of job characteristics, financial variables and other variables, and $t$. It also depends on $T$, the tastes of those working at $t$. The

\footnotetext{
${ }^{30}$ Housebold wealth includes housing equity and financial wealth, bat not pension or Social Security wealth.

${ }^{17}$ Their meding wealth is $\mathbf{\$ 0}$ thousand higher, also the highest of any group.
} 
hazard of leaving full-time work at 62 given full-time work at $t$ is just $1-P 62$. Our particular functional form makes this hazard linear in age and imposes the restriction that the effect of the explanatory variables on $\mathrm{P} 62$ is independent of age. For example, our functional form says that the effect on P62 of having a pension is the same for someone of age 51 as someone of age 61 . This is a substantial restriction that probably should be relaxed in future work. Similarly the effects of changes in $T$ as a population ases (and those with greater tastes for leisure retire) can only enter through age. However, even with a more general functional form we could not separate in cross-section interactions between age and the explanatory variables from interactions between taste changes and the explanatory variables.

In addition to age and the 38 calegorical variables, our specification for P62 has 13 categorical variables for industry, 16 for occupation, pension and health insurance variables, job flexibility variables, wage and income variables and personal characteristics including education, health starus, and houschold wealth. Our strategy is to use hypothesis testing to reduce the number of right-hand variables. For a time we will concentrate on a discussion of the equation for P62, and later outline the differences with the equation for P65.

The following table shows the sequence of tests and the outcomes.

\section{Outcomes of tests of hypotheses}

\begin{tabular}{llll} 
Variables & Hypothesis & Outcome & Decision \\
\hline 16 Occupation & $\begin{array}{l}\text { All coefficients } \\
\text { are zero }\end{array}$ & $\begin{array}{l}\text { Failed to } \\
\text { reject }\end{array}$ & Do not consider further \\
13 Industry & $\begin{array}{l}\text { All coefficients } \\
\text { are zero }\end{array}$ & Reject & Include in regressions \\
38 job characteristics & $\begin{array}{l}\text { All coefficients } \\
\text { are zero }\end{array}$ & $\begin{array}{l}\text { Failed to } \\
\text { reject }\end{array}$ & $\begin{array}{l}\text { Test subset of job characteristics } \\
\text { interacted with health status }\end{array}$ \\
$\begin{array}{l}\text { SI interactions between } \\
\text { job characteristics and } \\
\text { health status }\end{array}$ & $\begin{array}{l}\text { All coefficients } \\
\text { are zero }\end{array}$ & $\begin{array}{l}\text { Failed to } \\
\text { reject }\end{array}$ & $\begin{array}{l}\text { Test subset of principal } \\
\text { components }\end{array}$
\end{tabular}

Even though in the final test we could not reject the null hypothesis that all the coefficients on the categorical job characteristics variables are zero, we considered that physical job demands might only affect the retirement plans of those in poor or fair health. Therefore, we inleracted PHYSICAL, LIFTING, BENDING, EYES, PACE, REPETITION, and DIFFICULT 
with indicators of self-assessed health status. ${ }^{\text {it }}$ None of the 51 estimated coefficients was statistically significant, and we could not reject the null hypothesis that all the coefficients are zero.

We next considered that although the job characteristics as a group are not significant, some combination of a subset may be. That is, the characteristics probably operate together in a complicated way to produce overall satisfaction from a job: if we knew how to combine them we might find that a subset does influence P62.

Our method will be to use the principal components of the job characteristics to reduce the dimensionality of the job description, while retaining their variation. We anticipate that the characteristics would reduce to just a few principal components that we could interpret. For example, a principal component for "physical" would have large coefícients (loadings) on physical effor, lifting and bending. We would use it (and others) to explain retirement, so as to be able to see if physically demanding jobs induce retirement.

Using nested hypothesis testing, we tested subsets of the principal components as follows:

Tests of the null hypothesis that the coeficients on principal components are zero

\begin{tabular}{cccc}
$\begin{array}{c}\text { principal } \\
\text { components }\end{array}$ & $\begin{array}{c}\text { Degrees of } \\
\text { freedom }\end{array}$ & $\begin{array}{c}\text { Estimated F- } \\
\text { statistic }\end{array}$ & $F(5 \%)$ \\
\hline $20-38$ & 19 & 1.25 & 1.59 \\
$11-19$ & 9 & 0.67 & 1.88 \\
$6-10$ & 5 & 0.87 & 2.21 \\
$1-5$ & 5 & 2.75 & 2.21
\end{tabular}

We could not reject the first three null hypotheses when taken in the order shown in the table, We do reject the null hypothesis that the coefficients are zero on the largest five principal components. Our basic specification will therefore include the five largest principal components. ${ }^{19}$ We will give a description of the components when we discuss our regression results below.

\footnotetext{
12 The health categories were excelfent or very good, good, and fair or poor.

19 The five largest components mccounted for $33 \%$ of the vrialion in the moment malsix of the job characteristics.
} 
The result of the nested hypothesis testing is a regression of $P 62$ on 67 variables. We estimated the regression over 2938 observations on full-time wage and salary workers aged 46-61 (wornen) or 51-61 (men). The estimated coefficients are in Table 7, parts A-E.

Part $\mathbf{A}$ has the coefficients on a set of variables that we call personal characteristics. The positive coefficienl on age shows that P62 behaves like a conditional probability: it increases by 0.11 over ten years. We interpret the earnings effect to be mostly a wage effect: ${ }^{20}$ although there is some variation in hours among these full-time workers, because they all work at least 35 hours a week, most of the variation is in the wage rate. The positive effect could, of course, be partly due to tastes both for long hours and a long work-life. The effect is moderate, although for large changes in earnirigs (but within the observed data) the would be substantial. For example, an income gain of $\$ 100$ thousand will increase P62 by 0.16 , which we estimate to be a gain in worklife of about one and one-half years. Household income is the combined income of both the respondent and spouse. We interpret the negative coefficient and the coefficient on wealth to show that leisure is a normal good. The coefficients on education and self-assessed health status have the expected signs.

The last two variables are responses to questions about the probability of living to 75 and to 85. Even holding health status constant we would expect that people who expect to live longer will want longer worklives to finance more years of retirement. Although the coefficients have the expected sign they are estimated to be small and they are not significant. ${ }^{21}$

Table 7, part B, has the estimate coefficients on financial incentives to work. Although we have already discussed the effects of earnings it is repeated here for comparison. To model the complex incentives of defined benefit pension plans (DB) we used responses to questions about features of the plans: workers with DB plans were asked the earliest age of eligibility for reduced benefits and the earliest age of eligibility for full benefits. ${ }^{22}$ From these responses we constructed five categorical variables to describe the structure of a plan. D2 is 1 if the age for early benefits is less than or equal to 62 and the age for full benefits is greater than 62 . We would expect that D2 would increase P62 compared with someone who could get full benefits at

\footnotetext{
${ }^{2}$ The variable is yearly earnings of the full-time worker.

${ }^{21}$ The range of PLIVE75 and PLIVE85 is from 0 to 1.0. See Hurd and MeGarry (1993a) for a discussion of these veriables.

${ }^{n}$ We only used information about the pension plan on their current job.
} 
62 or younger, and possibly even compared with someone with no pension. Thus, a defined benefit plan does not necessarily increase the retirement probability at all ages; at some ages the stucture of the plan may decrease the probability of retiring. We defined D3 through D6 as indicated in the table. The reference group among those with $\mathrm{DB}$ plans has both full and partial benefits at age 62 or less.

About half of our sample has a DB plan on the current job and 62 percent of them say they are eligible for full henefits at 62 or earlier. Early availability of benefits reduces $P 62$ considerably, 0.12 (out of an average of 0.47 ) compared with a worker who has no pension plan. If the age for full benefits is greater than $62(\mathrm{D} 2=1) \mathrm{P} 62$ increases by 0.16 . For this group the net effect of the plan is to increase P62 by $-0.12+0.16=0.04$ compared with workers with no plan. Apparently workers want to remain on the job until they can get full benefits. If early benefits are not available until after age $62(D 3=1)$, P62 increases by an additional 0.04 so that P62 is about 0.08 higher than for workers with no pension. If AGEFULL or AGE-EARLY is missing P62 is even higher, but if both are missing, P62 is about the same as among those with no pension plan: possibly the respondent knows so little about the plan that its features cannot inform the determination of P62.

The DC eligibility variable comes from a question about the youngest age a worker could leave the employer and start receiving a monthly pension from the plan. ${ }^{z}$ The estimated results are qualitatively about the same as with the DB plans, but smaller. This is to be expected because the DC plans do not have the sharp accruals and actuarial adjustments that DB plans have. Besides a wealth effect, they apparenty influence retirement through a liquidity effect: otherwise, there would be no reason for availability after 62 to affect retirement at 62 , In a similar way a liquidity constraint may be responsible for Social Security causing a retirement spike at 62.

Having health insurance on the job increases P62, although the effect is not large. Much larger effects come from having health insurance available to retires. This is important, of course, because Medicare is not available until age 65 . The effects are monotonic according to how much the employer pays for the health insurance. This may represent a pure wealth effect, but it probably also reflects some uncertainty about the longer-run continuation of health insurance: an employer who pays for the insurance probably has a greater commitment to keeping the retiree in the employer's risk pool.

\footnotetext{
${ }^{23}$ This question is asked only if the pension can be received as monthly benefits.
} 
Table 7, part C, has the coefficjents related to job characteristics. Of the principal components only number 3 has a significant coefficient, and even in that case the effect is smal]: the change in component 3 from the 25 percentile to the 75 percentile is 2.41 , which increases $\mathrm{P} 62$ by 0.02 . The loadings on component 3 show that it is associated with jobs that have some physical requirements at the level of "some of the time" or "most of the time" but not "all of the time." The jobs are not especially demanding mentally, yet by a measure of mental requirements that we developed, it has the highest rank of the five largest components. Along other dimensions component 3 has demands "some of the time," and it is at a maximum when requirements are moderate rather than "all the time" or "not at all."

Principal component 2 has practically no effect even though tha loadings show that the jobs associated with large values of principal component 2 are physically dernanding. Furthermore, it has by far the largest value in our index of physical requirements. ${ }^{24}$ The prediction from other studies in the literature (Holden, 1988) would be that component 2 will have a strongly positive association with retirement; yet that is not what our results show.

Component 1 is associated with jobs that seem to have few requirements of any kind. The jobs are not demanding, either physically or mentally; they do not require much attention and they are not particularly stressful. Therefore, it would seem that component 1 would not have much association with retirement. Its negative effect may well be the result of boredon on the job.

The coefficient on component 4 is almost as large as the coefficient on component 3 , and it is almost significant at the 5 percent level $(P=0.066)$. The loadings on component 4 show fewer physical demands than component 3 , and it has the smallest value in our index of physical demands, and almost the lowest index of blue collar occupations. This component generally takes large values when job demands are moderate rather than intense of not at all. If workers value jobs that are somewhat but not overly challenging, this component should delay retirement. Component 4 has less variation than 3 (2.11 from the 25 th percentile to the 75 th percentile), so its effect on P62 is smaller than the effect of 3.

The loadings on principal component 5 are small so that we have not attempted an interpretation.

In a variation on our basic specification, we added interactions between the five principal

\footnotetext{
${ }^{2}$ See Hurd and McGarry (1993b), which is an expanded version of this paper, for information about the principel components.
} 
components and three categorical health variables (excellent or very good, good, and fair or poor). The interactions were significant at the $5 \%$ level $(P=0.031)$, mostly due to an interaction between principal component 4 and health of fair or poor. The following table gives the coefícients on component 4 and standard errors.

Estimated effects of principal component 4 on P62 by health status

\begin{tabular}{ccc} 
& Health starus \\
\hline Excellent or very good & Good & Fair or poor \\
\hline 0.007 & $*$ & 0.046 \\
$(0.010)$ & & $(0.015)$
\end{tabular}

Normalization. The exefficient is -0.001 (0.008)

Our interpretation of component 4 was that it is associated with jobs that are only moderately demanding. Furthermore, it has by far the lowest score on our index of physical demands, and, along with component 5, has the lowest index of blue collar jobs. It has practically no effect on prospective retirement of those with good, very good or excellent health. Among those in fair or poor health an increase from the 25th percentile to the 75th percentile (2.11) is associated with an increase in P62 of 0.097 .

We conclude that moderate job requirements increase the likelihood of working past age 62. In general, physical requirements do not lead to earlier retirement. However, there is some suggestion that physical job demands interact with health: those in poor health who have jobs that are not physically demanding have higher probabilities of working past 62. Even so, compared with the effects of DB plans and other aspects of the environment, the effects of job characteristics are rather small.

A blue collar occuparion has practically no effect, and union status, while statistically significant, is not very large (Table 7, part C). Apparently aspects of jobs that are typically unionized such as the availability and structure of $\mathrm{DB}$ plans cause early retirement, not union states itsolf.

The next two sets of variables are our measures of age discrimination on the job, and their coefficients have the expected pattern of signs. For example, if the respondent disagrees strongly with the statement that younger workers are preferred to older workers in promotion, 
P62 is greater by 0.03 . If the respondent disagrees that his co-workers think that older workers ought to retire before age 65, P62 is greater by 0.06 (significant at the 5 percent level). This difference is larger than that associated with a unionized job or a DC pension plan.

The next two variables are associated with job flexibility aimed particularly at older workers: respondents were asked if older workers can move with the same employer to a job that is less demanding and pays less. Although the coefficients are not significant, they show that when they cannot make such a job change, P62 is lower by 0.02 to 0.04 .

The last variables are constructed from a question about whether there is a normal retirement age for co-workers or for this kind of job. The normalization is on the age range 63 to 65 . The effects are large: when the usual retirement age is 62 or less, P62 is 0.19 lower than when it is 63 to 65 . This is about as large as the variation induced by DB plans. In that 40 percent of the sample has a usual retirement age of 62 or less, R_AGE62 is responsible for reducing the mean of $\mathbf{P 6 2}$ by about 0.076 . The other variables have reasonable coeflicients: when the normal retirement age is missing we get a mix of the first category and the normalization; when it is greater than $65, \mathrm{P} 62$ is increased.

We conclude that the usual physical and mental measures of job characteristics are not very important in determining anticipate retirement probabilities. Undoubtedly this is partly due to sorting across jobs and partly to compensations in demanding jobs that make it easier to retire. For example, DB plans may be structured to allow early retirement in physically demanding jobs. However, there are physically demanding jobs that do not have pensions, so we would expect to find some effect anyway. We do not.

There is modest evidence that an employer who allows older workers to change to an easier job will retain them as shown by the coefficients on O_DEMT3 and O_DEMT4. By far the most important effect in the table is related to usual retirement age. Of course, usual retirement age is not static either over time or across jobs, and it is probably parly caused by job requirements. To the extent that we have included those job requirements, however, the results show the importance of convention in decision making.

We presented in Table 6 the cross-tabulations of P62 by our measure of hours flexibility. Table 7, part D, has comparable results from the regression, and therefore, takes into account job and personal variables that may be correlated with hours restrictions. Generally the effects are attenuated. For example, in Table 6 the difference in P62 between those who can increase hours and those who cannot but do not want to is 0.07 . In Table 7, part D, the difference is 0.048 (HRSUPOK). But even that differenee disappears with age: by age 60 there is practically none. 
Among those who cannot increase hours, P62 is greater by 0.077 when the constraint is binding (HRSUP). Our interpretation is that these workers will substitute for the binding hours constraint by working more years. The difference fals with age so that by age 60 it is just 0.026 . This reduction may reflect the fact that the constraint, while still binding, becomes less importanl with age as tastes shift toward leisure.

Among those who cannot reduce hours, the most interesting comparison is between those who want to reduce hours and those who do not want to. When the constraint is binding, Pf2 is lower by 0.06 (HRSOWN). That is, those who must work more hours than they would like to anticipate retiring by age 62 with a greater probability. We saw in Table 5 that people in these jobs work moce hours and have greater wealth; but the estimated effect of the hours constraint is greater than of the wealth effect. The difference in wealth is $\$ 84$ tho 1 .and, which, according to our estimates in Table 7, part A, teduces P62 by about 0.01 whereas the constraint reduces it by 0.06 .

The final two variables in Table 7 , part $\mathrm{D}$, are also related to the choice set broadly speaking. The first is the subjective probability the respondent will lose his or her job during the year. An interpretation of the negative coefficient is that P62 lakes into account a number of contingencies: for example, someone who is certain to be laid off would have low probabilities of P62 because most who are laid off during their 50 's eventually retire rather than take another job. On the other side, if the respondent thinks the probability of finding another job is high, P62 will be increased. In that PFINDJOB varies from zero to one, the predicted change in P62 can be as large as 0.08 .

Table 7, part $E$, has the coefficients on the categorical variables representing the industry of the job. We will not discuss them as they are not the focus of this paper, but we note that there are some rather large differences: 0.12 between public administration and retail.

It is beyond the scope of this paper to investigate systematically the joint retirement decision of husbands and wives. Nonetheless, to check the robustness of our results we added to an auxiliary regression a number of variables that prior research has shown to influence the retirement decision of a spouse. ${ }^{25}$ They included the spouse's employment status, the spouse's probability of working past 62 , and the difference in the ages of the husband and wife. Although these variables themselves influence P62, their inclusion had practically no effect on any of the estimated coefficients on job characteristics, including pensions, health insurance, hours

\footnotetext{
${ }^{25}$ See Fiurd, 1990.
} 
restrictions and so forth. We concluded that for the goal of this paper we did not reed to investigate further the joint retirement decision of husbands and wives.

The rather odd structure of $\mathrm{DB}$ plans has led to the ldea that they were designed to aliow workers to leave physically dernanding jobs at about the age when the jobs becarne too demanding. If that were the case, the coefficients on job characteristics should be rather small when the DB variables are included in the P62 equation because the structure of the DB plan would adequately account for variation in $\mathrm{P} 62$. Conversely, if the $\mathrm{DB}$ plan variables are excluded, the coefficients on job characteristics should become large. However, in estimates not shown, there is almost no change in the coefficients on the five principal components when we leave the DB variables out of the P62 equation,

We repeated all the calculations we have been discussing but using P65 as the left-hand variable. However, our hypothesis testing strategy led to a different outcome. With respect to P65 we could not reject the null hypothesis that all the coefficients on the occupation variables are zero nor the null hypothesis that all the coefficients on the industry variables are zero. When we imposed these restrictions and tested the coefficients on the 19 smallest principal components we rejected the null hypothesis that the coefficjents are jointly equal to zero. Therefore we were left with a different model. In the results we report, $\mathrm{P} 65$ depends on all 38 principal components (which is the same as dependance on all the job characteristics), but not on the industry or occupation variables. We also excluded the varjables that differentiate the ages for full and partial benefits under DB and DC plans since almost everyone has both full and partial availability at 65 or earlier. Any variation in the age for benefit qualification should have no effect on P65 as long as the age is 65 or less. We will not describe the results in the same detail we did with P62 because there are far fewer large or significant estimated coefficients. Rather we will discuss novel or imporant findings.

The eamings and wealth effects are significant and similar to those for P62. The coefficient on PLIVE85 is estimated to be 0.10 (with standard error of 0.03 ). This is a rather large fraction of the average of $P 65(0.23)$. Because the health variables are included and have the expected signs, this is evidence that those with greater life expectancy plan longer worklives.

As discussed above, in our main results we excluded D2 through D6 and DC AGEE because they should not matter for P65. To satisfy ourselves that they do not matter, and, incidentally, to provide additional evidence that their operation in the P62 equation comes from, the structure of the DB plans and not from some unexplained correlation with other job or personal characteristics, we temporarily added them back into the P65. equation. Table 8 has the 
coefficients from that regression and for purposes of comparison the corresponding coefficients from the regression of P62.

The first line shows the effects of having a DB plan with full benefits available at 62 or younger compared with not having a DB plan. Both P62 and P65 are considerably smaller. The interesting comparison is in lines 2 and 3 . When full benefits are availabie after age 62, P62 increases by 0.16 , but P65 is almost not affected. (Almost all can get full benefits at 65 or younger.) This is good evidence that the respondents krow the details of the pension plans and adjust their subjective probabilities to take account of the plans. When partial benerits are available only after age 62, P62 increases by 0.20 compared with the base case. P65 also increases. This may be due to the ambiguity of the questions on the probabilities of working: someone who plang to retire while 65 because $D B$ benefits are not available until age 65 , may give a high value of $\mathrm{P} 65$. In any event the coefficient in the $\mathrm{P} 65$ equation is substantially smaller than in the P62 equation.

The effects of the availability of health insurance on P65 are smaller than on P62 (Table 9). This should be expected because of the availability of Medicare at 65 . Health insurance on the job increases $P 65$ by 0.054 which just balances having fully paid retiree health insurance: in that it is available whether working or not, it should not influence the retirement choice.

Among the job characteristics only four of the 38 are significant at the $5 \%$ level, and none of the physical characteristics is significant. The only coeffisient that is substartially different from the corresponding coefficient in the P62 equations is that on freedom in work decisions. This is consistent with some findings in the literafure: according to surveys of managers the main negative characteristic of older workers is that they become rigid (Hurd, 1993).

As was the case in the P62 equation, the usual retirement age among co-workers or on the job had a large effect (Table 10). What is particularly interesting is the difference in the coefficients between the two equations. As discussed earlier a usual retirement age of 62 or less has a large effect on P62 but it has little effect if it is greater than 65 . In the P65 equation, however, the difference between jobs with a usual retirement age of 62 or less and those with a usual retirement age of 63-65 should be smalt, although probably not zero because of the ambiguity in the question about P65. Finally, P65 should be much higher in jobs in which the usual retirement age is greater than 65 .

These palterns are exactly what is found in Table 10. The effects are large: the variation in P65 is 0.32 as the normal retirement age varies from 62 or less to 66 or over. This variation 
is larger than the mean of P65.

The effects of having flexibility in the choice of hours of work are similar in the P65 equation to the effects in the P62 equation. Table 20 includes the coefficients from the P62 equation for comparison, and it shows the results from evaluating the age-interactions terms. ${ }^{26}$ As before, those who would like to increase hours plan to work more years, but the effect is smaller than in the P62 equation. Those who would like to reduce hours give lower probabilities of working past 65, and the effect increases with age. This is compatible with the idea that as workers age, what was a good job match at a younger age becomes increasingly a bad match, and their response in the face of hours rigidity is to retire. By age 60 the difference $(0.063)$ is a large fraction of the mear: $(0.228)$.

A result not shown in the table is that someone who is optimistic about finding a job should he or she be laid off (PFINDJOB) reports higher values of $\mathrm{P} 65$, about 0.07 higher (significant).

\section{Conclusion}

We have studied the influence of a number of job characteristics on the probability of working past 62 or 65 . The physical or mental demands of the job seem to have only a modest influence on prospective retirement. We imagine this happens because of interactions between the actual job demands and personal capabitities. People choose jobs that are in consonance with their abilities. Thus, a job that objectively requires lifting will attract workers capable of lifting, and that job requirement will not necessarily lead to labor force withdrawal. If capabilities change with age, mismatches will develop between job requirements and capabilities. But if the change in capabilities is even, job characteristics will not appear to influence retirement: the uniformly increasing mismatch between capabilities and jobs will just appear as an increase in the basetine retirement hazard rate as people age.

If capabilities change differentially with age, job characteristics can have an observable influence on retirement. For example, if all workers lose their physical capabilities sooner than their mental capabilities, a mismatch will develop between workers in physically demanding jobs, even though there was no mismatch earlier in the work career. Then, workers in physically demanding jobs will tend to retire earlier. Similarly, if some workers fall into (physically) worse

\footnotetext{
${ }^{26}$ The age effects on incressing bours are very small, so we do not show them.
} 
health, they will tend to retire earlier if they work in physically demanding jobs. We found some modest evidence for such an effect among those in fair or poor health: the principal component that is associated with the least physically demanding jobs is associated with a longer worklife.

Our results indicate that a number of seemingly negative job characteristics are at an optimum when they are moderate. For example, having some suress on the job seems to be better than never having stress or always having stress. Of course, this could be due to correlations between the job characteristic and other unmeasured job attributes. It could aiso be due to a human desire not to be bored. Whatever the explanation, the results imply that often a set of calegorical job characteristic variables cannot be reduced to a scaler.

Even though the physical and mental job characteristics are not important determinants of P62 and P65, other nonfinancial aspects of the job are important. For example, if the usual retirement age in a particular type of work is less than or equal to $62, \mathrm{P} 65$ is predicted to be 0.12 by our regression; yet if the usual retirement age is greater than $65, \mathrm{P} 65$ is predicted to be 0.44 . This change is even grearer than changes associated with changing the structure of DB pension plans.

The ability to change hours of work or to move to a less demanding job with the same employer increase the prospective retirement age. This is in accord with the stated desire of workers to reduce work effort gradually, rather than moving from full-time work to complete retirement (Jondrow, Brechling and Marcus, 1987).

Pensions have a strong influence on prospective retirement, which agrees with previous findings about the relationship between pensions and actual retirement. A more novel finding is the effect of the availability of health insurance, both for employees and for retirees. Workrelated health insurance is, of course, a financial reward from working, but it is also a job characteristic: it provides access to a risk pool; it reduces or even eliminates the importance of prior conditions; and it eliminates the risk of losing insurance following large medical expenses. It is difficult, if not impossible, for an individual to purchase these characteristics.

Iл summary, we found that job characteristics are important determinants of prospective retirement, but not those whith have been traditionally studied such as physical reguirements. Taken as a whole, however, they do show the importance of nonmonetary aspects of the work environment on the labor force behavior of older workers. We base this conclusion on the relationship between job characteristics and prospective retirement which, of course, leaves operh the possibility that actual retirement will depend on different job characteristics. 
Figure 1

Retirement hazard rates

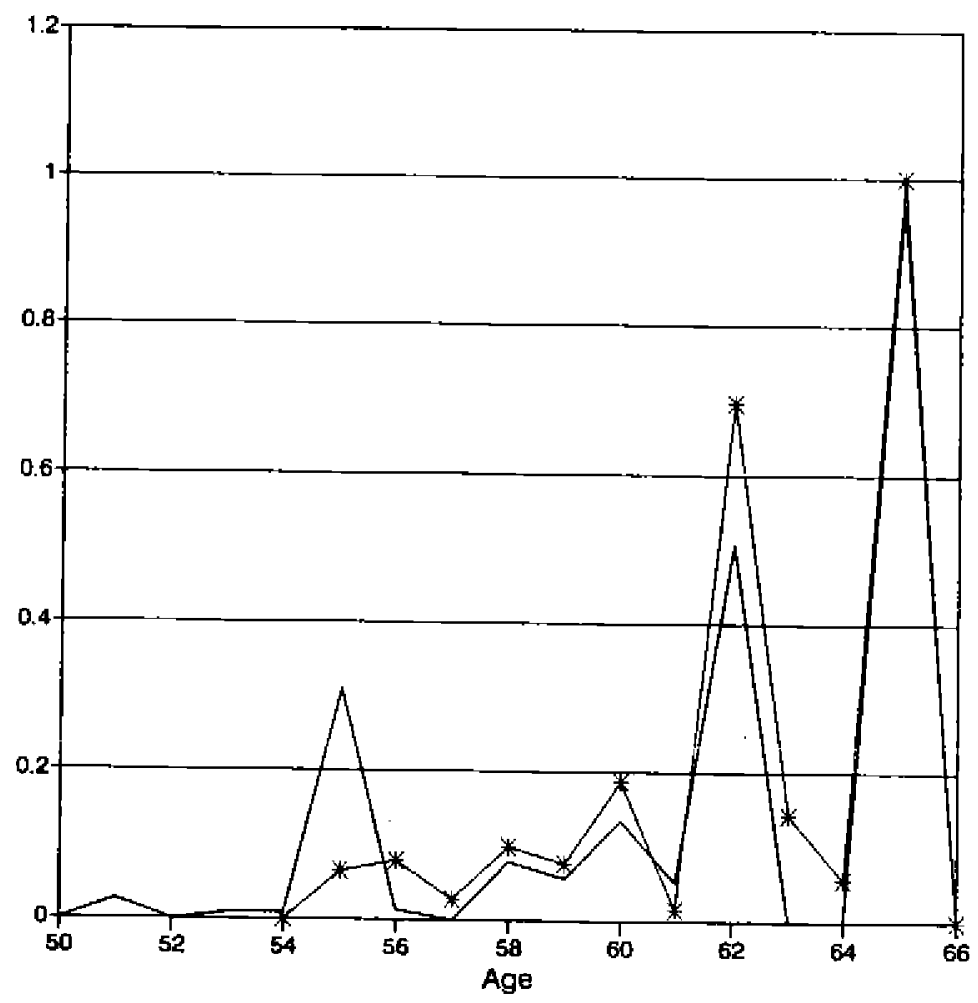


Figure 2

Prob. of working past 62 or 55

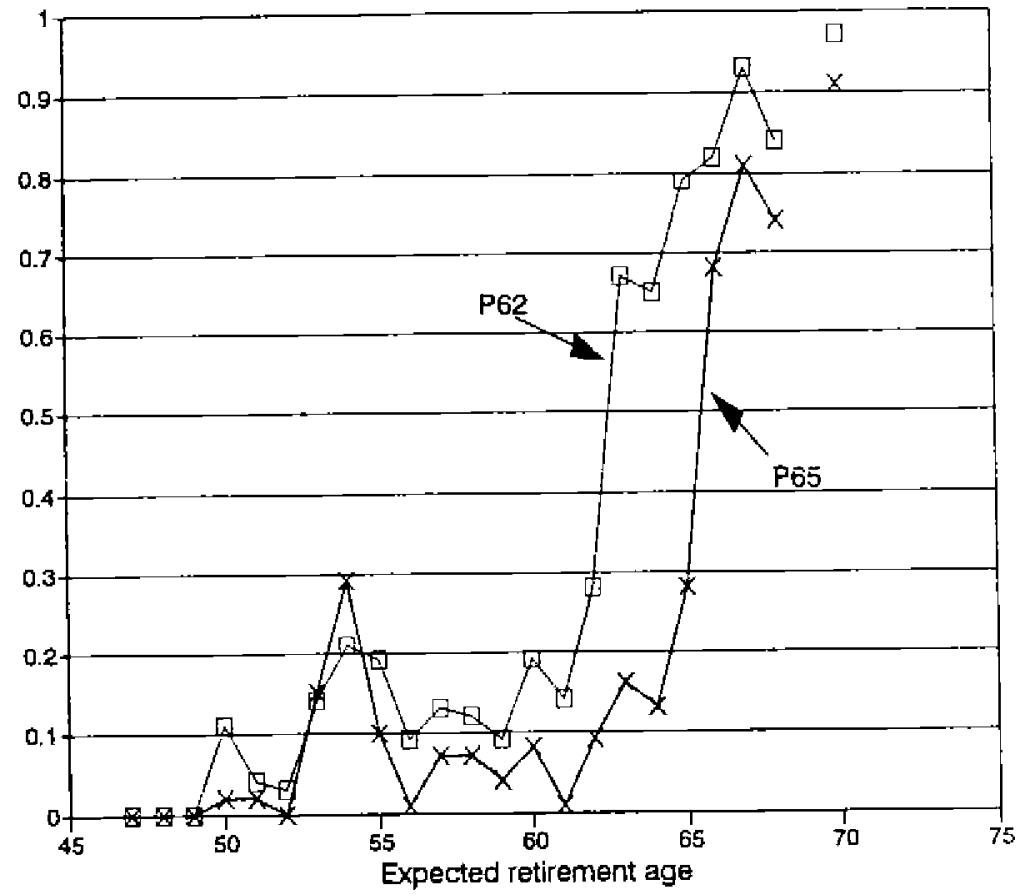

丹 Probability $62 \nrightarrow$ Probability 65 
Table 1

Probability of Working Full-time

\begin{tabular}{lccc}
\hline Work plans & $\begin{array}{c}\text { Distribution } \\
\text { (percent) }\end{array}$ & P62 & P65 \\
\hline Stop altogether & 24.3 & .311 & .087 \\
Never stop & 6.0 & .627 & .437 \\
Not thought, no plan & 43.4 & .555 & .293 \\
Work fewer hours & 18.2 & .441 & .214 \\
Change kind, work for self & 12.7 & .420 & .188 \\
All & $104.6^{\circ}$ & .468 & .227 \\
\hline Source: Authors' calculations from HRS. & & \\
More than 100\% because multiple answers given. & \\
\hline
\end{tabular}


Table 2

Probability of working after age 62 or 65 : Effects of job characteristics

\begin{tabular}{|c|c|c|c|}
\hline Job characteristic & After 62 & After 65 & Explanation \\
\hline \multicolumn{4}{|l|}{ LIFTTNG } \\
\hline 1,2 & - & - & all or most \\
\hline 3 & -0.018 & 0.010 & some \\
\hline 4 & $-0.054^{\dagger}$ & -0.006 & none \\
\hline
\end{tabular}

EYES

$\begin{array}{cccc}1 & -0.032 & -0.032^{*} & \text { all } \\ 2 & - & - & \text { most } \\ 3,4 & -0.051^{\dagger} & -0.012 & \text { some or none }\end{array}$

REPETITION

$\begin{array}{cccc}1 & -0.019^{\dagger} & -0.046^{*} & \text { all } \\ 2 & - & - & \text { most } \\ 3,4 & 0.033^{\dagger} & 0.007 & \text { some or none }\end{array}$

FREEDOM

$\begin{array}{cccc}i & 0.031^{+} & 0.062^{*} & \text { all } \\ 2 & - & - & \text { most } \\ 3 & -0.005 & 0.018 & \text { some } \\ 4 & -0.033 & -0.009 & \text { none }\end{array}$

DIFFICLLT ${ }^{*}$

$\begin{array}{cccc}1 & -0.017 & -0.014 & \text { strongly agree } \\ 2 & - & . & \text { agree } \\ 3,4 & 0.039^{\circ} & 0.051^{\circ} & \text { disagree }\end{array}$

STRESS

\begin{tabular}{cccc}
1 & -0.027 & -0.012 & strongly agree \\
2 & - & - & agree \\
3,4 & $-0.039^{*}$ & -0.017 & disgree \\
\hline
\end{tabular}

Source: Authors' calculations from HRS.

Note: 'Significant at $5 \%$ level. 'Significant at $10 \%$ level.

JJob requires more difficult things than it used to 
Table 3

Distribution of responses (percent):

"Again thinking of your job, this time please indicate how much you agree or disagree with each statement"

\begin{tabular}{|c|c|c|c|c|c|}
\hline & Number & $\begin{array}{c}\text { Strongly } \\
\text { agree }\end{array}$ & Agree & Disagree & $\begin{array}{l}\text { Strongly } \\
\text { disagree }\end{array}$ \\
\hline $\begin{array}{l}\text { F85c: In decisions about } \\
\text { promotion my employer gives } \\
\text { younger people preference } \\
\text { over older people }\end{array}$ & 3325 & 4 & 14 & 67 & 16 \\
\hline $\begin{array}{l}\text { F85d: My co-workers make } \\
\text { older workers feel that they } \\
\text { ought to retire before age } 65\end{array}$ & 3336 & 3 & 14 & 66 & 18 \\
\hline $\begin{array}{l}\text { F85e: My employer would } \\
\text { let older workers move to a } \\
\text { less demanding job with less } \\
\text { pay if they wanted to }\end{array}$ & 3276 & 3 & 31 & 55 & 12 \\
\hline
\end{tabular}

Table 4

Distribution of Workers: Hours Flexibility (percent)

\begin{tabular}{lcccc}
\hline & \multicolumn{4}{c}{ Can you increase hours? } \\
\cline { 2 - 5 } $\begin{array}{l}\text { Can you decrease } \\
\text { hours? }\end{array}$ & Yes & No, don't want to & No, want to & All \\
\hline Yes & 12.9 & 8.3 & 2.8 & 24.1 \\
No, don't want to & 18.1 & 32.7 & 11.5 & 62.3 \\
No, want to & 5.0 & 7.9 & 0.8 & 13.6 \\
All & 36.0 & 48.9 & 15.1 & 100.0 \\
\hline Source: Authors' calculations & from HRS. & & \\
\hline
\end{tabular}


Table 5

Hours Restrictions: Job and Personal Characteristics

\begin{tabular}{|c|c|c|c|c|c|c|}
\hline Hours flexibility & $\begin{array}{c}\text { Weekly } \\
\text { hours }\end{array}$ & $\begin{array}{l}\text { Wage } \\
\text { rate }\end{array}$ & $\begin{array}{l}\text { Annual } \\
\text { eamings } \\
\text { (thous.) }\end{array}$ & Education & $\begin{array}{l}\text { BLUEC } \\
\text { (percent) }\end{array}$ & $\begin{array}{c}\text { HHI } \\
\text { wcalth } \\
(100 \mathrm{k}) \\
\end{array}$ \\
\hline Can increase hours & 45.3 & 14.45 & 34.2 & 13.1 & 24 & 2.33 \\
\hline \multicolumn{7}{|l|}{ Cannot increase hours } \\
\hline Do not want to & 42.3 & 12.69 & 28.0 & 12.8 & 28 & 1.98 \\
\hline Want to & 40.6 & 10.97 & 23.2 & 11.8 & 42 & 1.19 \\
\hline Can decrease hours & 45.2 & 13.52 & 31.9 & 13.0 & 19 & 2.36 \\
\hline \multicolumn{7}{|l|}{ Cannot decrease hours } \\
\hline Do not want to & 42.1 & 13.11 & 28.8 & 12.6 & 32 & 1.72 \\
\hline Want to & 43.9 & 12.68 & 28.9 & 12.8 & 29 & 2.56 \\
\hline
\end{tabular}

Source: Authors' calculations from HRS. 
Table 6

Average Probability of Working Full-time: Hours Flexibility

\begin{tabular}{lcc}
\hline \hline Hours constraint & After age 62 & After age 65 \\
\hline Can increase hours & 0.50 & 0.26 \\
Cannot increase hours & & \\
Do not want to & 0.43 & 0.20 \\
Want to & 0.51 & 0.25 \\
(Difference) & -.08 & -.05 \\
& $(0.02)$ & $(0.02)$ \\
Can decrease hours & & \\
Cannot decrease hours & 0.51 & 0.27 \\
Do not want to & & \\
Want to & 0.48 & 0.23 \\
(Difference) & 0.37 & 0.15 \\
\hline
\end{tabular}

Source: Author's calculations from HRS.

Note: Standard errors in parentheses. 
Table 7, Part A

Probability of working past 62: personal characteristics

\begin{tabular}{|c|c|c|c|}
\hline Variable & Coefficient & Standard err. & Explanation \\
\hline AGE & $0.0109^{\circ}$ & 0.0029 & Age- 50 \\
\hline EARNINGS & $0.0016^{+}$ & 0.0004 & individ eamings (lk) \\
\hline INCHH & $-0.0012^{-}$ & 0.0003 & household income (1k) \\
\hline WEALTH & $-0.0106^{*}$ & 0.0026 & household wealth (100k) \\
\hline WHITE & $0.0434^{\circ}$ & 0.0172 & 1 if white \\
\hline SEX & $0.0398^{\circ}$ & 0.0161 & 1 if male \\
\hline NSS_EXP & 0.0389 & 0.0271 & expects Soc. Sec. income \\
\hline EDUC1 & 0.0038 & 0.0193 & Less than H.S. \\
\hline EDUC3 & $0.0483^{\circ}$ & 0.0162 & More than H.S. \\
\hline HLTH2 & -0.0165 & 0.0170 & health very good \\
\hline HLTH3 & $-0.0482^{\circ}$ & 0.0182 & health good \\
\hline HLTH4 & $-0.0666^{\circ}$ & 0.0262 & health fair \\
\hline HLTH5 & 0.0003 & 0.0513 & health poor \\
\hline PLIVE75 & 0.0383 & 0.0350 & probability live to 75 \\
\hline PLIVE85 & 0.0467 & $0.03: 0$ & probability live to 85 \\
\hline \multicolumn{4}{|c|}{ (coefficients continued in Part B) } \\
\hline
\end{tabular}

Source: Authors' calculations from the HRS.

Note: Mean of $P 62=0.47$.

Note: "Significant at $5 \%$ level. 
Table 7, Part B

Probability of working past 62: Financial Incentives

\begin{tabular}{|c|c|c|c|}
\hline Variable & Coefficient & Standard err. & Explanation \\
\hline \multicolumn{4}{|c|}{ (continued from Part A) } \\
\hline EARNINGS & $0.0016^{\circ}$ & 0.0004 & Indiv Earnings (1k) (sect N) \\
\hline DB & $-0.1181^{\circ}$ & 0.0199 & 1 if defined benefit \\
\hline D2 (DB) & $0.1637^{\circ}$ & 0.0235 & 1 if agefull $>62 \&$ age-early $\leq 62$ \\
\hline D3 (DB) & $0.1998^{\circ}$ & 0.0363 & $\downarrow$ if agefull $>62 \&$ age-early $>62$ \\
\hline D4 (DB) & $0.2474^{\circ}$ & 0.0666 & 1 if agefull $>62 \&$ age-early $=$ \\
\hline D5 (DB) & $0.2197^{\circ}$ & 0.0576 & 1 if agefull $=\cdot \&$ age-early $\leq 62$ \\
\hline D6 (DB) & $0.1048^{\circ}$ & 0.0472 & 1 if agefull $=\cdot \&$ age-early $=$ \\
\hline DC & $-0.0533^{\circ}$ & 0.0235 & 1 if defined conlribution \\
\hline DC_AGEE & 0.0739 & 0.0496 & 1 if $d c \&$ age-early $>62$ \\
\hline DC_AGEEM & 0.0357 & 0.0271 & 1 if $d c \&$ age-early $=$ \\
\hline HEATHINS & 0.0324 & 0.0273 & 1 if health ins. on job \\
\hline DHEALTHI & -0.0270 & 0.0195 & 1 if retiree hithins avail, not paid \\
\hline DHEALTH2 & $-0.0843^{\circ}$ & 0.0209 & 1 if retiree hlthins avail, some paid \\
\hline DHEALTH3 & $-0.1132^{\circ}$ & 0.0243 & 1 if retiree hlthins avail, all paid \\
\hline DHEALTH6 & -0.0024 & 0.0230 & 1 if retiree hlthins avail $=$ \\
\hline
\end{tabular}

Source: Authors' calculations from the HRS.

Note: agefull = earliest age for full benefits under DB plan; age-early = earliest age for any benefits under DB or DC plan. - means the datum is missing.

Note: "Significant at $5 \%$ level. 
Table 7, Part C

Probability of working past 62: Job characteristict

\begin{tabular}{|c|c|c|c|}
\hline Variable & Coefficient & Standard err. & Explanation \\
\hline \multicolumn{4}{|c|}{ (continued from Part B) } \\
\hline PRIN1 & -0.0050 & 0.0033 & principle component 1 \\
\hline PRIN2 & 0.0008 & 0.0037 & principle component 2 \\
\hline PRIN3 & $0.0085^{\circ}$ & 0.0039 & principle component 3 \\
\hline PRIN4 & 0.0080 & 0.0043 & principle component 4 \\
\hline PRIN5 & -0.0072 & 0.0044 & principle component 5 \\
\hline BLUEC & 0.0101 & 0.0207 & blue collar occupation \\
\hline UNION & $-0.0450^{\circ}$ & 0.0165 & union job \\
\hline O_PRMT3 & 0.0066 & 0.0187 & F85C: younger preferred: disagree \\
\hline O_PRMT4 & 0.0348 & 0.0269 & younger preferred: strongly disagree \\
\hline O_RET3 & $0.06+3^{\circ}$ & 0.0196 & F85D: older ought to retire: disagree \\
\hline O_RET4 & $0.0580^{\circ}$ & 0.0270 & older ought to retire; strongly disggree \\
\hline O_DEMT3 & -0.0214 & 0.0148 & F85E: can move to less demanding job: disagree \\
\hline O_DEMT4 & -0.0419 & 0.0242 & can move to less demanding job: strongly disagree \\
\hline R_AGE62 & $-0.1889^{*}$ & 0.0159 & F90: usual retirement age on this job $<=62$ \\
\hline R_AGE66 & 0.0717 & 0.0507 & usual retirement age on this job $>=66$ \\
\hline M_R_AGE & $-0.0662^{*}$ & 0.0514 & usual retirement age on this job $=$. \\
\hline \multicolumn{4}{|c|}{ (coefficients continued in Part D) } \\
\hline
\end{tabular}

Source: Authors' calculations from the HRS.

Note: "Significant at 5\% level. 
Table 7, Part D

Probability of working past 62: hours restrictions

\begin{tabular}{lccl}
\hline Variable & Coefficient & Standard err. & Explanation \\
\hline \multicolumn{3}{c}{ (continued from Part C) } \\
HRSUPOK & $0.0483^{*}$ & 0.0240 & Could increase hrs: $1=$ yes \\
A_UPOK & -0.0039 & 0.0040 & AGE*HRSUPOK \\
HRSUP & $0.0768^{*}$ & 0.0326 & Would you like to increase: $1=$ yes \\
AGE_UP & -0.0052 & 0.0055 & AGE*HRSUP \\
HRSDWNOK & 0.0031 & 0.0264 & Could you reduce hrs: 1 =yes \\
A_DWNOK & -0.0021 & 0.0044 & AGE*HRSDWNOK \\
HRSDWN & -0.0600 & 0.0320 & Would you like to reduce: $1=$ yes \\
AGE_DWN & 0.0002 & 0.0053 & AGE*HRSDWN \\
PLAYOFF & -0.0357 & 0.0274 & Prob. lose job during year \\
PFINDJOB & $0.0817^{*}$ & 0.0187 & Prob. find new job \\
& (coefficients continued in Part E) & \\
\hline
\end{tabular}

Source: Authors' calculations from the HRS.

Note: 'Significant at $5 \%$ level. 
Table 7, Part E

Probability of working past 62: Industry

\begin{tabular}{lccl}
\hline Variable & Coefficient & Standard err. & Explanation \\
\hline & (continued from Part D) & \\
IND1 & -0.0189 & 0.0594 & Agriculture/Forestry/Fishing \\
IND2 & -0.0002 & 0.0346 & Mining and Construction \\
IND3 & -0.0152 & 0.0273 & Manuf: Non-durable \\
IND5 & $-0.0585^{\circ}$ & 0.0291 & Transportation \\
IND6 & 0.0168 & 0.0374 & Wholesale \\
IND7 & $-0.0759^{\circ}$ & 0.0309 & Relail \\
IND8 & $-0.0712^{\circ}$ & 0.0328 & FIRE \\
IND9 & -0.0099 & 0.0396 & Business/Repair Serv \\
IND10 & -0.0713 & 0.0483 & Personal Services \\
IND11 & -0.0364 & 0.0582 & Entertainment/Rec \\
IND12 & -0.0109 & 0.0246 & Professional Services \\
IND13 & 0.0556 & 0.0329 & Public Admin \\
\hline
\end{tabular}

Source; Authors' calculations from the HRS.

Note: Industry 4, durable manufacturing, is reference.

Note; "Significant at $5 \%$ level.

Note: $\mathbf{R}^{2}=0.22$ 
Table 8

Defined Benefit Plans: Comparison of Effects on P62 and P65

\begin{tabular}{|c|c|c|c|c|}
\hline \multicolumn{2}{|c|}{ Structure of DB plan } & \multirow[b]{2}{*}{$\begin{array}{l}\text { Distribulion of } \\
\text { respondents }\end{array}$} & \multicolumn{2}{|c|}{ Coefficients on } \\
\hline $\begin{array}{l}\text { Youngest age for } \\
\text { reduced benefits }\end{array}$ & $\begin{array}{l}\text { Youngest age } \\
\text { for full benefits }\end{array}$ & & $\mathrm{P} 62$ & $\mathrm{P} 65$ \\
\hline less than 63 & less than 63 & 0.62 & $-.12^{*}$ & $-.10^{\circ}$ \\
\hline less than 63 & greater than 62 & 0.21 & $0.16^{\circ}$ & 0.04 \\
\hline greater than 62 & greater than 62 & 0.07 & $0.20^{\circ}$ & $0.08^{\circ}$ \\
\hline (missing) & greater than 62 & 0.02 & $0.25^{\circ}$ & $0.20^{\circ}$ \\
\hline less than 63 & (missing) & 0.03 & $0.22^{\circ}$ & 0.08 \\
\hline (missing) & (missing) & 0.04 & $0.10^{\circ}$ & $0.14^{\circ}$ \\
\hline
\end{tabular}

Source: Authors' calculations from the HRS.

Note: "Significant at $5 \%$ level.

Table 9

Effects of availability of health insurance on P62 and P65

\begin{tabular}{lcc}
\hline \hline Sinucture of health insurance & P62 & P65 \\
\hline Health insurance on job & 0.032 & $0.054^{\circ}$ \\
Retiree insurance available & & \\
Not paid & -.026 & -.001 \\
Partially paid & $-.084^{\circ}$ & $-.053^{\circ}$ \\
Fully paid & $-.113^{\circ}$ & $-.055^{\circ}$ \\
Availability missing & -.002 & $0.040^{\circ}$ \\
\hline
\end{tabular}

Source: Authors' calculations from HRS.

Note: 'Significant at $5 \%$ level. 
Table 10

Effect of Usual Retirement Age on Probability of Working Past Age 62 or 65

\begin{tabular}{lcc}
\hline \hline Usual retirement age & 62 & 65 \\
\hline Less than or equal to 62 & $-.19^{\circ}$ & $-.11^{\circ}$ \\
Greater than 62 and less than 66 & - & - \\
Grcater than 65 & -.07 & $0.21^{*}$ \\
(missing) & -.07 & 0.01 \\
\hline
\end{tabular}

Source: Authors' calculations from HRS.

Note: "Significant at 5\% level.

Table 11

Effect of Hours Flexibility on Probability of Working Past Age 62 or 65

\begin{tabular}{lcc}
\hline Hours flexibility & 62 & 65 \\
\hline Cannot increase hours & & \\
Don't want to & - & \\
Want to & $0.078^{*}$ & 0.045 \\
Cannot decrease hours & & \\
Don't want to & - & - \\
Want to & - & - \\
Age $=50$ & -.060 & -.046 \\
Age $=60$ & -.058 & -.063 \\
\hline
\end{tabular}

Source: Authors' calculations from HRS.

Note: "Significant at 5\% level.

Note: Results for $\mathrm{P} 62$ are from Table 7 , part $\mathrm{C}$ 


\section{References}

Bartel, Ann (1982) "Wages, Nonwage Job Characteristics and Iabor Mobility" Industrial and Labor Relations Review. 35(4) Fp. 578-589.

Berkovec, James and Steven Stem, 1991, "Job Exit Behavior of Older Men," Econometrica, 59 (1) pp. 189-210.

Brown, Charlie (1980) "Equalizing differences in the Labor Market" Quarerly Joumal of Economics, 94(1) pp. 113-133.

Filer, Randall and Peter A. Petri (1988) "A Job-Characteristics Theory of Retirement," Review of Economics and Statistics, Vol. 70(1) pp123-129.

Gustman, Alan L. and Thomas L. Steinmeier. "Partial Retirement and the Analysis of Retirement Behavior," Industrial and Labor Relations Review. April 1984, Vol. 37, No. 3, pp. 403-415.

Gustman, Alan L. and Thomas L. Steinmeier. The Effect of Partial Retirement on the Wage Profiles of Older Workers," Industrial Relations. Spring 1985, Vol.24, No.2, pp.257-265.

Gustman and Steinmeier (1986) "A Disaggregated Structural Analysis of Retirement by Race, Difficulty of Work and Health," Review of Economics and Statistics, V.68(3) PP 509-513.

Hayward, Mark D., William R. Grady, Melissa A. Hardy, and David Sommers (1989), "Occupational Influences on Retirement, Disability, and Death." Demography, Vol. 26 (3) pp. 393-409.

Holden, Karen (1988) "Physically Demanding Occupations, Health, and Work After Retirement: Findings from the New Beneficiary Survey" Social Security Bulletin, Vol. 51(11) pp3-15.

Hurd, Michael D., 1990, "The Joint Retirement Decision of Husbands and Wives, " in Issues in the Economics of Aging, D. Wise (editor), The University of Chicago Press, pp. 231-254.

Hurd, Michael D., 1993, "The Effect of Labor Market Rigidities on the Iabor Force Behavior of Older Workers," NBER Working Paper 4462.

Hurd, Michael D. and Kathleen McGarry, 1993a, "Evaluation of Subjective Probahility Distributions," presented at the HRS Early Results Workshop, Ann Arbor, September.

Hurd, Michael D. and Kathleen McGarry, 1993b, "The Relationship Between Job Characteristics and Retirement," presented at the HRS Early Results Workshop, Ann 
Arbor, September.

Iams, Howard, 1987, "Jobs of Persons Working After Receiving Retired-Worker Benefits," Social Security Bulletin, 50, (11).

Jondrow, Jim, Frank Brechling and Alan Marcus, 1987, "Older Workers in the Market for Part-Time Employment, " in The Problem Isn't Age, Ed: Steven H. Sandell, New York: Praeger, pp. 84-99.

Mitchell, Olivia S. 1982, "Fringe benefits and labor mobility" Joumal of Human Resources, XVII (2) pp.286-298.

Mitchell, Otivia S., 1983, "Fringe Benefits and the Cost of Changing Jobs," Industrial and Labor Relations Review, 37, 1, (October) pp. 70-78.

Quinn, Joseph F. (1977) "Microeconomic Determinants of Early Retirement: A CrossSectional View" Jounal of Human Resources, Vol. 12(3) pp. 329-346.

Quinn, Joseph, Richard Burkhauser, and Daniel Myers, 1990, Fassing the Torch: The Influence of Economic Incentives on Work and Retirement, Kalanazoo: The Upjohn Institute.

Ruhm, Christopher, 1990, "Bridge Jobs and Partial Retirement," Journal of Labor Economics, 8 (4), Pp. 482-501.

Rust, John P., 1990, "Behavior of Male Workers at the End of the Life Cycle: an Empirical Analysis of States and Controls," in Issues in the Economics of Aging, Ed:

David A. Wise, Chicago: The University of Chicago Press, Pp. 317-378.

Sum, Andrew and W. Neal Fogg, 1990, "Profile of the Labor Market for Older Workers," in Bridger to Retirement, Ed: Peter B. Doeringer, Ithica: ILR Press, Cornell University, pp. 33-63. 